\title{
Entre sobreviventes e bichas dos tempos dourados - memória, homossexualidade e sociabilidade na cidade de Goiânia, Brasil*
}

\section{Camilo Braz**}

\section{Resumo}

Neste trabalho, interpreto antropologicamente algumas narrativas sobre os primeiros estabelecimentos de lazer noturno voltados para (ou ocupados por) homossexuais ou entendidos, na cidade de Goiânia, capital de Goiás. Os relatos permitem apontar para a importância desses estabelecimentos no que diz respeito à constituição de redes de amizade, sociabilidade ou de certa movimentação homossexual na cidade, entre as décadas de 1970 e 1980. Por outro lado, permitem uma discussão preliminar sobre as relações e tensões entre memória, homossexualidade, preconceito e resistência.

Palavras-chave: Goiânia, Homossexualidade, Memória, Mercado, Geração.

\footnotetext{
Recebido para publicação em 12 de fevereiro de 2013, aceito em 17 de agosto de 2015.

** Professor de Antropologia, na Faculdade de Ciências Sociais (FCS) da Universidade Federal de Goiás, Goiânia, GO, Brasil.camilobraz@gmail.com 
504 Entre sobreviventes e "bichas dos tempos dourados"

Among Survivors and "Fags from The Wonder Years" - Memory, Homosexuality and Sociability in Goiânia, Brazil

In this work I interpret some narratives about the first nighttime venues meant for or occupied by homosexuals or entendidos in Goiânia, capital of Goiás. The accounts show the role of these establishments in the formation of friendship networks, sociability or of a certain homosexual scene in the city between the 1970s and 1980s. On the other hand, they lead to a preliminary discussion about the relationships and tensions between memory, homosexuality, prejudice and resistance.

Keywords: Goiânia, Homosexuality, Memory, Marketplace, Generation. 


\section{Introdução}

Em 2010, recém-chegado a Goiânia, passei a co-coordenar no Ser-Tão, Núcleo de Estudos e Pesquisas em Gênero e Sexualidade, junto a Luiz Mello, uma pesquisa sobre a trajetória do Movimento LGBT (lésbicas, gays, bissexuais, travestis e transexuais) em Goiás. ${ }^{1}$ O surgimento desse movimento está associado ao enfrentamento da epidemia da aids, num cenário local de incipiente visibilidade dos estudos sobre homossexualidade nas universidades, de representações geralmente negativas da população LGBT na mídia, de ampliação crescente do mercado segmentado voltado para gays e lésbicas e de estreitamento cada vez maior das relações entre o movimento LGBT e o Governo Federal, por meio do Ministério da Saúde (Braz, Mello et al., 2011).

Por meio da análise das entrevistas, realizadas na ocasião com ativistas, professores/as universitários/as e parlamentares envolvidos/as com questões LGBT, foi possível perceber algumas ambivalências nos discursos a respeito do mercado comumente denominado como "GLS"2 (gays, lésbicas e simpatizantes) ou simplesmente "gay", e suas possíveis relações com as demandas do movimento organizado. Se muitas vezes ressaltaram-se os bares, boates $e$ outros estabelecimentos comerciais como importantes para tal população, na medida em que permitem a expressão de afetos e o estabelecimento de amizades em um contexto sociocultural ainda bastante marcado por preconceito $e$ violência, por outro lado afirmou-se que a luta política deveria ser pela possibilidade de circulação das pessoas em todos os espaços:

\footnotetext{
1 "Movimentos sociais, direitos humanos e cidadania: um estudo sobre o movimento LGBT em Goiás", financiada pela Fundação de Amparo à Pesquisa do Estado de Goiás (FAPEG).

2 Trarei entre aspas termos ou expressões que, seguindo as ideias de Judith Butler, possam ser lidos como provisórios, criticáveis, em disputa. O efeito das aspas seria o de desnaturalizar os termos, designá-los como lugares de debate político (Butler, 1998). Em itálico, trarei termos e expressões êmicas, utilizadas pelos entrevistados.
} 
comerciais ou não, "GLS" ou não. Apesar disso, muitas entrevistas ressaltaram a importância de parcerias, ainda que esparsas, com estabelecimentos comerciais para ações $e$ demandas do movimento LGBT no estado. Nesse sentido, destacaram as Paradas do Orgulho LGBT, que ocorrem em Goiânia desde 1996 (Braz e Mello, 2012), como momentos especiais em que tais aproximações se materializam - muito embora houvesse falas críticas apontando que o problema é que elas se restringem a esses períodos. Tal restrição se dá, para os sujeitos entrevistados, seja pela falta de apoio por parte dos/as empresários/as às organizações e aos grupos da sociedade civil, seja pelo fato de que o próprio movimento LGBT local não se apropria estrategicamente do mercado, propondo atividades e parcerias.

Assim, no processo de análise dos dados daquela pesquisa, surgiu a ideia de investigar as trajetórias locais relativas ao mercado segmentado ${ }^{3}$ voltado ao lazer $e$ à sociabilidade homossexual, o que levou à presente investigação. ${ }^{4}$ Neste trabalho, interpreto antropologicamente algumas narrativas sobre os primeiros estabelecimentos de lazer noturno voltados para (ou ocupados por) homossexuais ou entendidos, na cidade de Goiânia, capital de Goiás. Os relatos permitem apontar para a importância desses estabelecimentos no que diz respeito à constituição de redes de amizade, sociabilidade ou de certa

3 O pressuposto aqui, a partir de pesquisas sócio-antropológicas já realizadas em outros contextos metropolitanos no Brasil (França, 2006 e 2012; Facchini, 2005 e 2008; Gregori, 2010; Fry, 2002; Braz, 2012a), é o de que a interpretação dos processos de constituição de categorias classificatórias que incidem na produção de corporalidades, subjetividades ou identidades em torno das homossexualidades pode ser complexificada ao levarmos em consideração as dinâmicas relativas ao mercado segmentado voltado a tais sujeitos. Neste trabalho, refiro-me especificamente ao mercado de lazer e sociabilidade noturna, composto em geral por bares e boates.

4 Realizada no Ser-Tão, Núcleo de Estudos e Pesquisas em Gênero e Sexualidade, e no Programa de Pós-Graduação em Antropologia Social (PPGAS) da UFG, intitulada "Memórias, Margens, Mercados: um estudo sobre locais "GLS" em Goiânia". Iniciada em 2011 e finalizada em 2014, contou com apoio da Fundação de Amparo à Pesquisa do Estado de Goiás (FAPEG). 
movimentação homossexual na cidade, entre as décadas de 1970 e 1980. Por outro lado, permitem uma discussão preliminar sobre as relações e tensões entre memória, homossexualidade, preconceito e resistência.

\section{Em pleno Bate-Papo}

Era uma segunda-feira de outubro de 2012, meu primeiro dia de recesso após o fim do semestre letivo ${ }^{5}$, em que aproveitaria para realizar algumas entrevistas para a pesquisa.

Passava das 19 horas. Deixei meu carro no estacionamento do Banana Shopping, um centro de compras popular localizado no centro da capital, em frente ao qual está localizada uma das três saunas gays da cidade, a Trés Chic. Caminhei para a Rua 3, que corta três das principais vias centrais da cidade - avenidas Araguaia, Goiás e Tocantins. Quase na esquina com a Araguaia, algumas mesas de plástico amarelas espraiavam-se na calçada, ao lado de algumas árvores e de um orelhão. Os clientes - todos eles homens, em média na faixa entre 45 e 60 anos, tanto "brancos" quanto "negros" ou "pardos", se utilizamos classificações do IBGE (Instituto Brasileiro de Geografia e Estatística) - conversavam em duplas ou pequenos grupos, tomando suas cervejas de garrafa bem geladas nas tulipas. Enquanto isso, perambulavam por entre as mesas, no ritmo ainda frenético de início de noite no Centro, pessoas mais jovens do que eles, em seus uniformes recém-saídos do trabalho ou a caminho dele, além de vendedores/as de quinquilharias, pedintes $e$ alguns bêbados. $\mathrm{O}$ único comércio aberto nos arredores do bar, além do shopping center popular onde eu estacionara, era uma drogaria, do outro lado da rua. Aproximei-me das mesas, saídas de um pequeno boteco de luz amarelada: tratava-se do Bate-Papo, barzinho existente desde 1982, famoso - desde aquela época - por abarcar, juntamente com outros bares centrais (como o Ceará, dentre outros

\footnotetext{
${ }^{5}$ Por conta de uma greve, as universidades federais reformularam seus calendários acadêmicos em 2012.
} 
estabelecimentos rememorados nas entrevistas que realizei) uma sociabilidade "homossexual" - sobretudo masculina e, em menor medida feminina, muito embora não tenham sido originalmente concebidos exclusivamente para tal público, tendo sido muitas vezes simplesmente ocupados por ele (Braz, 2014).

Liguei para Marcos ${ }^{6}$, ator/performer que fez parte de um famoso grupo de teatro que atuou em Goiânia do início da década de 1990 até a morte de seu criador, Júlio Vilela, em 2006. Foram eles os responsáveis pelo espetáculo Jú Onze e 24 paródia do talk show da Rede Globo de Televisão então estrelado por Jô Soares, chamado Jô Soares Onze e Meia -, que para muitos teve impacto na visibilização das homossexualidades localmente, ao trazer para o palco homens vestidos de mulher que realizavam performances musicais, recriavam números de dança (como as apresentações de Madonna), além de esquetes cômicas.

O Ju deu uma encorpada nessa coisa gay... eu sempre digo que às vezes as pessoas não reconhecem, mas o Ju deu uma encorpada nessa coisa gay. Por quê? Eram homens que faziam papeis de mulheres! (Marcos).

Aguardei por Marcos do outro lado da rua, sentado na sarjeta, enquanto observava o movimento no bar. Após cerca de meia hora, ele chegou e eu fui até seu encontro. Sentamos em uma das mesas e, após as apresentações, os comentários sobre o trânsito, o clima ameno que fazia após o período de seca e tendo a cerveja sido devidamente solicitada ao garçom, liguei o gravador. Em pouco tempo, Paulo, um amigo dele (que ele havia convidado para nosso encontro), que trabalha como fotógrafo, também fez parte da equipe técnica da trupe do Jú e atua em uma ONG voltada para atendimento a portadores do vírus da aids, chegou.

6 Os nomes aqui citados foram inventados a fim de preservar o anonimato dos sujeitos da pesquisa. 
Camilo: Então, a gente vai fazer uma conversa a três?

Marcos: A três.

Camilo: Pode ser!

Marcos: Eu tava falando pra ele dos bares, Paulo... Mas ele queria saber a questão das épocas e eu não lembro... você é melhor que eu pra isso.

Paulo: Vamos mexer no chip! (risos).

Alguns minutos depois, um terceiro amigo de Marcos, chamado Raí, carioca que vive em Goiânia desde criança, juntouse a nós.

Raí: Posso sentar? Eu atrapalho?

Paulo: Eu estou tentando lembrar de um bar que ficava na [rua] oito, esquina com a quatro...

Raí: Oito, esquina com a quatro? Zepelin?

Paulo: Zepelin!

Marcos [ar nostálgico]: Ah, o Zepelin...

Raí [tom irônico]: Não sei como eu lembrei dele! [risos] Era gay esse bar? [risos] Meu pai ficava falando [faz voz grossa]: não passa na porta desse bar!

[risos]

Paulo: Mas foram muitos bares naquela época...

Lá estava eu, paulista morador de Goiânia há cerca de dois anos, professor universitário e com certa dificuldade para conhecer interlocutores/as para a pesquisa, sentado em uma mesa de um dos primeiros bares voltados para a sociabilidade entre homossexuais ou entendidos ${ }^{7}$ da cidade, cercado por uma turma de amigos na faixa dos 48 aos 53 anos, que se conheciam desde a adolescência e estavam dispostos a compartilhar comigo, de um

7 Eles não utilizam mais o termo "entendido", preferindo afirmar-se como "gays" ou como "homossexuais". Mas frisaram o quanto era dessa forma que se falava "naquela época", como referência aos anos 1970. Quando utilizam termos como "entendidos" ou "homossexuais" - ou ainda, em tom propositalmente jocoso, "bichas" - tais sujeitos estão, portanto, dizendo seu pertencimento geracional esses são modos mais "antigos" ou "usados antigamente" de nominação. Ver, a respeito, Guimarães (2004). 
modo extremamente amigável, suas memórias e experiências. $\mathrm{O}$ gravador foi então deixado no centro da mesa e, em pleno BatePapo, batemos o nosso próprio papo de maneira mais livre, embora norteado pelas questões da investigação.

Cheguei até eles por intermédio de Cleber, cabeleireiro a quem eu havia entrevistado naquele mesmo dia algumas horas antes, em seu salão de beleza, localizado em um bairro da zona sul da cidade. Cleber, por sua vez, havia sido indicado por Sandro, ator/performer que chegou a participar do Ju Onze e 24, embora seja mais novo que os demais (tinha quase 43 anos quando o entrevistei) sendo até hoje frequentador assíduo de casas noturnas da cidade, sobretudo aquelas conhecidas por serem sem rótulos. ${ }^{8}$

Naquela tarde, durante nossa conversa no salão, Cleber ligava para seus amigos insistentemente para tentar lembrar datas e nomes de estabelecimentos. Aproveitava, então, para falar sobre mim e perguntar se eles aceitariam colaborar com a pesquisa.

Cleber [ao telefone, com Marcos]: Bicha! você é a salvação da pátria, vou passar seu telefone pra um menino chamado Camilo. Ele vai te fazer umas perguntas sobre os points gays da nossa época dourada, sabe?

Assim, também pude conhecer, naquela mesma semana, além dos rapazes que encontrei no Bate-Papo, Mário, empresário aposentado que, como o próprio disse, sempre pertenceu à alta sociedade goianiense e é figura presente em colunas sociais. E também Tales, conhecido artista plástico local, e seu amigo Gerônimo, a quem ele convidou para a entrevista que fizemos em seu ateliê, localizado próximo à Avenida Bernardo Sayão, num

8 Há atualmente em Goiânia locais que, apesar de não se apresentarem como "GLS", são bastante frequentados por jovens gays, lésbicas, bissexuais ou, ainda, por sujeitos que se dizem "sem rótulos" no que tange à sexualidade. Dois deles foram etnografados por Giórgia de Aquino Neiva (2014). 
setor famoso pelo comércio popular de roupas e tecidos na capital.

Desse modo, eu que já havia conversado com muitos/as empresários/as de bares e boates $^{9}$, além de alguns/algumas poucos/as clientes, acabei entrevistando naquela semana uma rede de amigos, frequentadores dos primeiros estabelecimentos da cidade voltados para a sociabilidade entre entendidos ou homossexuais e que se conhecem desde muito jovens ou adolescentes - alguns deles estudaram juntos quando crianças.

Meu interesse neste trabalho é o de buscar interpretar as narrativas desse grupo de amigos a respeito da importância de alguns dos estabelecimentos por eles rememorados na constituição de redes de amizade e sociabilidade "homossexual" na cidade de Goiânia de final dos anos 1970 e início dos anos 1980.

\section{Narrativas e contextos}

Nesse sentido, uma série de narrativas de empresários/as relembraram uma Goiânia de meados de finais dos anos 1970, uma cidade então considerada média, em plena ditadura militar, quando começaram a surgir os primeiros bares frequentados ou ocupados por homossexuais ou entendidos (Braz, 2014).

Voltando à conversa no Bate-Papo, quando indaguei a Marcos, Paulo e Raí se eles sabiam qual teria sido o primeiro bar de Goiânia voltado para tal público eles responderam em

9 Cabe destacar, aqui, a atuação de estudantes de Iniciação Científica: Matheus França, que investigou cinemas pornôs, e Tanieli Silva, cujo recorte deu-se em relação aos locais voltados para lésbicas em Goiânia. Ambos realizaram entrevistas com frequentadores/as e empresários/as. Também agradeço a atuação de estudantes do PPGAS/UFG: o trabalho de transcrição de uma entrevista realizado por Raphael Silveira, a realização de uma entrevista e a transcrição de várias delas por Giórgia Neiva. E agradeço, especialmente, a Katianne Almeida, cuja atuação, engajamento, seriedade e parceria foram fundamentais para a realização de muitas entrevistas. Ela também fez a análise dos materiais de divulgação de bares e boates (Almeida, 2012). Sem esse trabalho em equipe, a investigação não teria sido possível. Agradeço a cada um/a dos/as estudantes envolvidos nela e, acima de tudo, a generosidade de cada entrevistado/a. 
uníssono: o Baculelê, bar surgido na capital nos anos 1970, localizado em um bairro afastado do centro e, naquela época, de difícil acesso (Braz, 2014). Segundo os entrevistados, só se podia ir até ele de carro, pois não havia linhas de ônibus que chegassem à região. Eles listaram vários outros lugares que surgiram no Centro alguns anos depois, pequenos botecos que passaram a ser frequentados (ou, nas palavras deles, ocupados) por homossexuais.

Paulo: Baculelê era um bar ali perto do Setor Jaó, Setor Santa Genoveva. Ele era um bar... afastado. Mas naquela época não existia um bar gay, entendeu? Eram as pessoas que faziam o bar se tornar gay, entendeu?

Nessa época, estava-se ainda longe de um contexto sociocultural de abertura e possibilidade da criação de uma política de identidades em torno das homossexualidades, capitaneada pelo movimento social, bem como de proeminência do mercado segmentado na criação de categorias classificatórias em torno das homossexualidades (França, 2006; Braz e Mello, 2012). Distante também do contexto atual, em que os efeitos do mercado segmentado voltado a gays e lésbicas em grandes cidades podem ser interpretados como um reforço ou cristalização de diferenças que incidem na produção de categorias classificatórias e, também, desigualdades, levando-nos a desconfiar de uma noção de sociabilidade voluntariosa, que não (re)produza desigualdades (Facchini; França e Braz, 2014). Apesar disso, é possível perceber pelas narrativas que já havia certa separação de "classe" operando entre os bares e sua localização: como dito, o Baculelê, de final dos anos 1970, estava afastado, sendo frequentado por homens mais velhos e que tinham carro para poder lá chegar. Já os bares centrais, de meados dos anos 1980, eram frequentados também por rapazes mais jovens e com menos dinheiro. Com exceção do Baculelê, todos os demais estabelecimentos surgidos ao longo dos anos 1980 - e são muitos, com uma grande rotatividade concentravam-se no centro da capital. 
Já nos anos 1990, surgem as duas primeiras boates declaradamente GLS da cidade: a Gênero e a Off (ambas localizadas no Centro). Pelas narrativas, é possível perceber que havia entre elas também certa distinção de público com base na classe social.

Marcos: Tinha assim, por exemplo: tinha o Off. Quinta e sexta era forte o Off. Todo mundo ia pro Off. Sábado era a Gênero.

Camilo: Ah, entendi. Era a boate.

Paulo: É como se fosse assim: hoje tem Total Flex e D!sel. Você passa na D!sel e encontra as pessoas mais finas. Vou na Total e encontro as pessoas mais...

Camilo: Quer dizer que isso já tinha, então.

[Todos concordam].

Paulo: As pessoas barraqueiras.

Camilo: Mas o barraqueiro tava aonde, só pra eu entender? [risos]

Marcos: Mas o barraqueiro dividia...

Paulo: A boate todos frequentavam. Era aquela mistura. Quando abria uma boate com um preço melhor, aí quem tinha poder aquisitivo maior ia pra lá e deixava as pobres. Assim aconteceu com o Off. Ele se tornou um inferninho. Por quê? Porque tinha as pessoas que não tinham tanta grana, só entrava por cortesia... porque a pessoa pra não perder os clientes, começava a dar cortesia... a bebida era mais barata... aí a outra era mais elitizada, assim... as pessoas tinham carro, se vestiam muito bem...

As narrativas dos frequentadores concordam com a interpretação de que os estabelecimentos comerciais surgidos nos anos 1990 em Goiânia já não se pautavam mais pela relativa invisibilidade prevalecente nos anos anteriores, sendo abertamente concebidos como "GLS" ou "gays", como os/as empresários/as já me haviam afirmado (Braz, 2014). Nesse sentido, são representativos os relatos acerca da criação de uma boate "GLS" que ficou muito famosa em Goiânia e mesmo em outras partes do Brasil. Trata-se da JUMP - the house of fun. A casa, criada em 
1996, funcionou durante quase 10 anos no Setor Oeste (região da cidade considerada nobre). Para além da questão de certa visibilidade positiva em torno da homossexualidade, percebe-se nas narrativas sobre a JUMP o distanciamento no que diz respeito à precariedade dos bares das décadas anteriores. Nesse sentido, ouvi em campo uma frase que atribuiu à idealizadora da JUMP ter trazido copos de vidro para Goiânia.

Em outro trabalho, interpretei o que estava sendo metaforizado a partir da polaridade entre copos de plástico ou copos de vidro (Braz, 2014). Trata-se da construção discursiva de uma separação entre dois contextos socioculturais distintos, que apontam para diferentes possibilidades de vivência das homossexualidades. Os primeiros bares da cidade são vistos como precários, afastados, escondidos. Não eram assumidamente GLS, tendo sido muitas vezes ocupados por homossexuais à revelia de seus/suas donos/as. A segunda metade da década de 1990 marca não apenas o surgimento do movimento LGBT localmente $e^{10}$, mas também a criação de estabelecimentos comerciais em Goiânia que não somente ganhavam inteligibilidade num contexto já de reivindicação de direitos, mas também de certa "glamourização" em torno das homossexualidades por parte do, agora, mercado GLS. Além disso, é nesse contexto que os lugares GLS passam a ocupar outras regiões da cidade. Assim como notado por Isadora França (2006) em São Paulo, o circuito GLS goianiense deixa de estar localizado no centro e segue paulatinamente em direção a bairros considerados mais nobres, como é o caso do Setor Oeste.

\footnotetext{
${ }^{10}$ Como mostra Mello (2005), o ano de 1995 pode ser tomado como marco para o movimento LGBT brasileiro, tendo em vista a fundação da Associação Brasileira de Lésbicas, Gays, Bissexuais, Travestis e Transexuais (ABGLT), a realização da Conferência da International Lesbian, Gay, Bissexual, Trans and Intersex Association (ILGA), no Rio de Janeiro, bem como a apresentação, pela então Deputada Marta Suplicy, do Projeto de Lei $n^{\circ} 1.151$, que dispunha sobre a parceria civil registrada entre pessoas do mesmo sexo. $\mathrm{O}$ primeiro grupo formalmente constituído no estado de Goiás, como organização nãogovernamental (ONG) LGBT, foi a Associação Ipê Rosa, criada justamente em 1995 (Braz e Mello, 2012).
} 
A partir dos anos 2000, tal processo parece se intensificar, como se pode perceber pela criação da boate The PUB, considerada hoje a mais cara da cidade e localizada no Jardim Goiás, um bairro de construções de alto padrão $e$ arranha-céus, às margens do Parque Flamboyant $e$ do shopping homônimo - que atualmente é o centro de compras mais elitizado da capital.

Assim, os copos de vidro acionam simbolicamente nas narrativas o início, nos anos 1990, de um cenário de produção de um repertório simbólico positivado em torno das homossexualidades em Goiânia, tanto por parte do movimento social quanto do mercado. $\mathrm{E}$, no caso do mercado, de (re)produção também de uma certa "glamourização", muitas vezes acionando velhos estereótipos que associam as homossexualidades, e especialmente os gays, seja à "festa", seja ao excessivo "poder de consumo" (Castañeda, 2006).

Além disso, dois elementos chamam a atenção nas narrativas sobre os lugares comerciais "GLS" em Goiânia de meados dos anos 1990. Em primeiro lugar, as dificuldades encontradas para sua criação. As entrevistas estão repletas de falas que apontam para uma série de resistências à criação de bares ou boates "GLS" na cidade (especialmente quando eles começam a ser criados fora do centro da cidade, em bairros mais valorizados da região sul, como os setores Oeste, Marista, Sul, Coimbra e Jardim América), que vão de entraves para a obtenção de alvarás, batidas policiais infundadas, abaixo-assinados realizados por vizinhos que não queriam morar ao lado de bares ou boates gays, até a depredação $e$ vandalização desses lugares, como exemplificam as narrativas sobre episódios de tijolos ou ovos atirados em suas portas, por exemplo.

Em segundo lugar, a produção de certa visibilidade positiva por parte desse mercado no mesmo momento em que o movimento LGBT surgia na cidade, num processo similar $e$ contemporâneo, por exemplo, ao descrito por Machado (2007) em Belo Horizonte. Nesse contexto, o mercado "GLS" goianiense deixa de ser percebido, pelos/as entrevistados/as, como relativamente precário e invisível. $\mathrm{E}$ passa, mais 
contemporaneamente, por certa segmentação a partir de marcadores sociais de diferença, o que incide na produção das categorias sociais que classificam seus/suas frequentadores/as de maneiras distintas. Assim, na atualidade, talvez seja possível perceber certo adensamento dos efeitos desse mercado no que diz respeito à (re)produção de diferenças e desigualdades, assim como se percebe na cidade de São Paulo (França, 2012; Facchini, 2008; Simões e Facchini, 2009). Hoje, são lugares que não apenas se destinam, mas que ajudam a produzir um repertório discursivo acerca de "públicos" distintos, por exemplo, no que diz respeito à idade. Um exemplo é a existência de festas matinês em boates gays, voltadas para adolescentes (Perilo, 2012). Outro exemplo, que aparece nas entrevistas realizadas, é o relativo preconceito em relação aos homens mais velhos nas boates gays.

Cleber: Adoro dançar sabe, mas hoje também tem muito preconceitos com as mariconas, sabe? Que se na época em que eu era jovem eu olhava as velhas e falava, hoje eu tô o reverso da medalha, né?

Maricona, nesse trecho, é uma categoria depreciativa que se aproxima, ao que parece, do uso de "tias" ou "tias velhas" em Florianópolis, como apontado por Carlos Eduardo Henning (2010) em sua etnografia sobre a "cena GLS" local. Trata-se, assim, de um modo depreciativo - e que, como lembra Henning, responsabiliza o sujeito por seu "mau envelhecimento" (Debert, 1999) - de referir-se a marcas etárias, opostas aos positivados "tiozões", que se aproximam do "coroa" estudado por Júlio Simões (2004) em São Paulo. A isso, soma-se a relativa ausência de lugares de lazer e sociabilidade para pessoas mais velhas em Goiânia, o que faz das saunas gays, ao menos para os entrevistados, mais do que simplesmente lugares de pegação, também de lazer e criação e manutenção de redes de amizade $e$ afeto.

Além da idade, os estabelecimentos contemporâneos ajudam a produzir - ou reforçar - também distinções no que tange 
ao gênero e à sexualidade, quando se percebe a relativa escassez de opções de lazer para lésbicas, em comparação com os espaços gays (Silva, 2012); à classe e raça/cor, quando se observa a existência de um bar na periferia, frequentado majoritariamente por rapazes negros nos domingos regados a chope e samba ${ }^{11}-0$ que evoca a análise empreendida por França (2010) sobre um "samba GLS" no centro de São Paulo; ou ao gênero e à classe, quando se pretende interpretar discursos frequentes que associam os poucos lugares frequentados por travestis à ideia de "risco" ou de "perigo". ${ }^{12}$ Tais ideias permitem trazer como hipóteses que, ao (re)produzir categorias classificatórias em diálogo com convenções de gênero, sexualidade, raça/cor, classe ou idade, de modo muitas vezes interseccional, esse mercado de lazer reforça diferenças que, muitas vezes, coadunam-se com a (re)produção de desigualdades.

De todo modo, neste trabalho não tenho a intenção de me aprofundar na interpretação de tais processos, uma vez que meu foco são os significados atribuídos aos primeiros locais comerciais de lazer voltados a homossexuais surgidos na cidade de Goiânia, rememorados pelos meus interlocutores no contexto de narrativas que alinhavam, de maneira nostálgica, memória, homossexualidade, amizade e sociabilidade.

\section{Entre sobreviventes e bichas dos tempos dourados}

A geração, em um sentido amplo, representa a posição $e$ atuação do indivíduo em seu grupo de idade e/ou de socialização no tempo. Daí o sentido dinâmico ou instável e plural que essa condição, de saída, representa (Britto da Motta, 2010:226).

\footnotetext{
11 Trata-se do Feirão do Chope, que é objeto da etnografia de Bruno Hammes (2014) no PPGAS/UFG.

${ }^{12}$ Nesse sentido, é de especial interesse buscar analisar as imagens produzidas a partir de flyers ou materiais de propaganda desses lugares, a fim de observar o modo como seus/suas clientes são idealizados/as, acionando muitas vezes tais marcadores sociais de diferença (Almeida, 2012).
} 
Ao resenhar as críticas e potencialidades do conceito de geração, bem como suas atualizações sociológicas $e$ antropológicas desde a clássica formulação de Karl Mannheim, Alda Britto da Motta lembra que uma das grandes dificuldades de sua aplicação diz respeito ao necessário reconhecimento dos riscos de homogeneização que o uso do conceito acarreta, caso não o interseccionemos com outros marcadores sociais de diferença, como classe, gênero, raça/cor ou sexualidade; perspectiva corroborada por Debert (1999) e Henning (2010). Gostaria de aproveitar aqui a sugestão de Britto da Motta, de que

$\mathrm{O}$ sentido mais plenamente sociológico, ou macrossociológico - geração, propriamente dita - designa um coletivo de indivíduos que vivem em determinada época ou tempo social, têm aproximadamente a mesma idade e compartilham alguma forma de experiência ou vivência, ou têm a potencialidade para tal (Britto da Motta, 2010:229).

Contudo, pretendo fazer isso seguindo de perto a sugestão de Henning, de tratarmos "geração (e juventude, assim como outras categorias do curso da vida) dentro do escopo das 'comunidades imaginadas', conforme proposto por Benedict Anderson" (Henning, 2010:18). Assim, utilizo o conceito de geração sob rasura, tendo em mente a necessidade de evitar uma suposta homogeneidade das experiências e memórias de sujeitos de uma mesma "geração", uma vez que as atuações de distintos marcadores sociais da diferença evocam sempre diferentes condições de existência (Bourdieu, 2007). De todo modo, chama a atenção, nas entrevistas realizadas, a recorrência de algumas clivagens.

A primeira delas diz respeito, inegavelmente, ao contexto da ditadura militar. Nesse sentido, as narrativas sobre a atuação dos recos (recrutas) são exemplares. Todos os entrevistados rememoram a grande diversão dos recos aos finais de semana, especialmente aos domingos à tarde. Saíam, de acordo com meus 
interlocutores, das imediações do Setor Jaó e vinham para o centro da cidade bater em viados.

Paulo: E as pessoas ficavam na calçada por segurança.

Ficavam olhando pra ver se vinha algum soldado.

Marcos: E as pessoas corriam pra todo lado! Tinha um amigo meu que... começou um quebra-pau lá e ele saiu correndo. Foram três recos atrás dele. E ele se enfiou em uma das vielas e se escondeu. Quando ele achou que tava tranquilo, ele saiu. Mas os recos ainda estavam procurando. Aí o reco deu uma botinada na cabeça dele.

Camilo: Mas assim, eles corriam atrás e alegavam o que?

Marcos: Não alegavam nada, eles só queriam bater em um viado.

Raí: Queriam bater em um viado.

Paulo: Naquela época a homofobia era muito grande.

Raí: E tinham os que pegavam em turma.

Camilo: Mas eles não prendiam?

Raí: Não, isso era reco, mesmo! Era recruta do exército.

Camilo: Ah, era só pra bater, então?

Raí: Exatamente.

Camilo: Não levava pra delegacia...

Raí: Não, não tinha essa coisa... a polícia ficava dando ronda. Eu lembro até que um amigo falava assim: "gente, cuidado, caixinha de joia!"

[risos]

Raí: Era o carro da polícia!

Marcos: Porque tem aquelas luzes em cima, né? [risos]

Raí: Mas na verdade seria para jogar joias lá dentro, sabe? [risos]

Camilo: Mas isso aconteceu em que época, mais ou menos?

Raí: Foi em 82, mais ou menos, não foi, Marquinhos?

Marcos: Não, foi mais...

Raí: Ah, foi mesmo...

Marcos: Porque quando eu saí pro mundo gay foi em 83 .

Tal narrativa sugere uma experiência da homossexualidade em Goiânia marcada pelo medo da violência - no caso de meus entrevistados, pelo fato de serem, em meados dos anos 1970 e 
1980, adolescentes sem grana que perambulavam por bares, becos $e$ botecos do centro da capital, frequentados por entendidos $e$ outros sujeitos considerados marginais ou fronteiriços - michês, prostitutas, artistas e boêmios. Também eles eram alvo, de acordo com as narrativas, de baculejos (batidas policiais) e curras.

Paulo: Eu tinha um medo de reco que você nem imaginava...

Chamou atenção, contudo, que a relação com os recos parecia evocar certa ambivalência. Se as narrativas a respeito deles estiveram repletas de episódios de violência, também foram permeadas, em outros momentos, pelo desejo. Não raro foi trazido nas falas o fascínio provocado, à época, por aqueles que eram (ou se diziam, como estratégia de valorização no mercado dos afetos) amantes de rapazes uniformizados e, acima de tudo, bofes ou homens de verdade (Fry, 1982). Sair com um reco era, de certo modo, motivo de prestígio entre as bichas.

Outra clivagem recorrente nas narrativas diz respeito à aids. Ao falar sobre os Estados Unidos no início dos anos 1980, Gayle Rubin (1984) afirma que, no momento em que os gays estavam conseguindo resultados positivos em sua luta para livrar-se do estigma que associava a homossexualidade à doença mental, eles se viram metaforicamente associados à imagem da degradação física fatal. A síndrome, suas características específicas e a forma de sua transmissão foram usadas para fortalecer velhos medos de que a atividade sexual, a homossexualidade e a "promiscuidade" levassem à doença e à morte.

Os veículos de comunicação disseminavam a ideia de que a Aids era uma doença moral, melhor dizendo, da imoralidade. A conotação direcionada às pessoas consideradas vulneráveis à epidemia transmitia a concepção de que elas estavam submetidas a grupos de risco, seja por uma doença, no caso dos hemofílicos, seja por comportamento sexual, ou ainda, por serem dependentes de drogas (Saletti Filho et al, 1999:52). 
Nesse sentido, tendo vivido quando muito jovens a fase da epidemia na qual ela ainda era chamada e propagandeada como peste gay ou câncer gay, todos os entrevistados mencionaram espontaneamente os impactos da aids, que, frequentemente, retornava às entrevistas, como um espectro. Percebi que não há, para eles, como rememorar suas experiências sem fazer menção a ela.

Paulo: Quando nós nos conhecemos, nós éramos menores de idade! (...) É por isso que a gente fala "Os Sobreviventes"... porque tiveram tantas pessoas que morreram...

De acordo com Michael Pollak (1992), desde os clássicos escritos sociológicos de Maurice Halbwachs (2006), nas primeiras décadas do século $\mathrm{XX}$, sabemos o quanto a memória deve ser entendida enquanto fenômeno coletivo ou social. Além disso, o autor sinaliza para a importância dos lugares de memória, aos quais as lembranças significativas são em geral ligadas. O principal argumento do autor é o de que a memória, sendo socialmente construída, é sempre um fenômeno sujeito a questões políticas, relacionadas a conflitos, disputas e relações de poder.

As idades dos meus colaboradores variavam, como afirmei, entre 48 e 53 anos. Nasceram, assim, em plena década de 1960, em um contexto já marcado pela ditadura militar, pela violência $e$ repressão. $\mathrm{Na}$ juventude, viveram também o horror da aids e assistiram à morte da maioria de seus amigos ou conhecidos. Mas entre o medo e a resistência, permaneceram. Bichas dos tempos dourados foi o modo como Cleber referiu-se a eles todos, em tom de brincadeira, quando o entrevistei. Mas também sobreviventes, como afirmou Marcos em nossa conversa, no Bate-Papo. E narraram suas memórias, nas quais os espaços para a sociabilidade homossexual goianiense são transformados em lugares, no sentido trazido por Isadora França (2012), ou seja, o de estabelecimentos carregados de significados por parte de sujeitos 
que, por outro lado, também se constituem por meio das experiências neles vividas.

Assim, ao contextualizar as narrativas sobre o surgimento dos lugares para a sociabilidade "homossexual" em Goiânia, é imprescindivel reconhecer os efeitos desse mercado no que diz respeito à possibilidade da criação de um "sentimento de comunidade" ou pertencimento (MacRae, 2005), além de sua importância na criação de redes de amizade. São relatos carregados de nostalgia, que rememoram a juventude, num período de (auto)descoberta da existência de "iguais", como, por exemplo, quando se narra a primeira ida a um lugar frequentado por homossexuais ou entendidos num contexto de pânico moral em torno de práticas então consideradas subversivas. Por tudo isso, é preciso reconhecer a relevância desse mercado a partir dessas narrativas, nas quais a descoberta $e$ a possibilidade de vivência da homossexualidade e da sociabilidade aparecem diretamente relacionadas às experiências vividas em estabelecimentos que, feitos lugares, chegam a figurar nos relatos quase como sujeitos. Eles eram parte dessa turma de amigos.

\section{Referências bibliográficas}

AlmEIDA, Katianne de Sousa. Flyers, hostess, sites e nomes na lista: um olhar antropológico sobre o mercado "GLS" goianiense. Trabalho apresentado no VI Congresso da ABEH. Salvador, ABEH, 2012.

BourdieU, Pierre. A distinção - crítica social do julgamento. Porto Alegre/São Paulo, Zouk/Edusp, 2007.

Braz, Camilo. À meia-luz... uma etnografia em clubes de sexo masculinos. Goiânia, Editora da UFG, 2012.

BRAZ, Camilo. De Goiânia a "Gayânia": notas sobre o surgimento do mercado "GLS" na capital do cerrado. Revista Estudos Feministas, vol. 22, nº 1, Florianópolis, UFSC, 2014, pp.277-296.

BRAz, Camilo et al. Movimentos sociais, direitos humanos e cidadania: um estudo sobre o movimento LGBT em Goiás. 2011. Relatório de pesquisa. 
BRAz, Camilo; Mello, Luiz. "Éramos 9 gays, 20 policiais e a imprensa local" - narrativas (de) militantes sobre as paradas do Orgulho LGBT em Goiás. In: PASSAMANI, Guilherme Rodrigues. (Org.). (Contra)Pontos: ensaios de gênero, sexualidade e diversidade sexual. O combate à homofobia. Campo Grande, Editora da UFMS, 2012.

BRITTO DA MOTTA, Alda. A atualidade do conceito de gerações na pesquisa sobre o envelhecimento. Revista Sociedade e Estado, vol. 25, n² 2. Brasília, UNB, maio-agosto de 2010.

Butler, Judith. Fundamentos Contingentes. Cadernos Pagu (11), Campinas, Núcleo de Estudos de Gênero-Pagu/Unicamp, 1998, pp.11-42.

CASTAÑEDA, Marina. "La homosexualidad y el mercado". La Nueva Homosexualidad. México, Paidós, 2006.

Debert, Guita Grin. A Reinvenção da Velhice: Socialização e Processos de Reprivatização do Envelhecimento. São Paulo, Edusp, 1999.

FACCHINI, Regina. Sopa de letrinhas? Movimento homossexual e produção de identidades coletivas nos anos 90. Rio de Janeiro, Garamond, 2005.

. Entre umas e outras: mulheres, (homo)sexualidade e diferenças na cidade de São Paulo. Tese de Doutorado em Ciências Sociais, IFCH/Unicamp, Campinas, 2008.

; FRANCA, Isadora Lins; BRAZ, Camilo. Estudos sobre sexualidade, sociabilidade e mercado: olhares antropológicos contemporâneos. Cadernos Pagu (42), Campinas, Núcleo de Estudos de GêneroPagu/Unicamp, jun. 2014, pp.99-140.

FRANÇA, Isadora Lins. Cercas e pontes. O movimento GLBT e o mercado GLS na cidade de São Paulo. Dissertação de mestrado, Antropologia Social, USP, São Paulo, 2006.

Consumindo lugares, consumindo nos lugares: homossexualidade, consumo e subjetividades na cidade de São Paulo. Rio de Janeiro, EdUERJ, 2012.

; SIMÕES, Júlio. "Do Gueto ao mercado". In: GREEN, J.; TRINDADE, R. (Orgs.). Homossexualismo em São Paulo e outros escritos. São Paulo, Editora da UNESP, 2005, pp.309-336. 
524 Entre sobreviventes e "bichas dos tempos dourados"

FRY, Peter. Da Hierarquia à Igualdade: a construção histórica da homossexualidade no Brasil. In: . Para Inglês Ver: identidade e política na cultura brasileira. Rio de Janeiro, Zahar, 1982, pp.87-115.

. Estética e política: relações entre "raça", publicidade e produção da beleza no Brasil. In: GOLDEMBERG, Miriam (org.). Nu e Vestido dez antropólogos revelam a cultura do corpo carioca. Rio de Janeiro, Record, 2002, pp.303-326.

Gregori, Maria Filomena. Prazeres Perigosos - erotismo, gênero e limites da sexualidade. Tese - Livre Docência. Instituto de Filosofia e Ciências Humanas, Unicamp, Campinas, 2010.

GuimarãES, Carmem Dora. O Homossexual Visto por Entendidos. Rio de Janeiro, Garamond, 2004.

HALBWACHS, Maurice. A memória coletiva. São Paulo, Centauro, 2006.

HAMMES, Bruno dos Santos. Entre o Armário e o "Feirão". Um estudo antropológico sobre mercado GLS, pertencimento e produção de identidades na periferia de Goiânia. Projeto de pesquisa de Mestrado. Antropologia Social, UFG, Goiânia, 2013.

HENNING, Carlos Eduardo. Olhares para o Conceito de Geração: uma etnografia das homossexualidades na adolescência e na velhice na cena GLS da cidade de São Paulo. In: Anais do II Seminário Nacional Sociologia e Política. Curitiba, UFPR, 2010 [http://www.academia.edu/401507/Olhares para_o conceito de Ger a\%C3\%A7\%C3\%A3o uma etnografia das homossexualidades na adolesc\%C3\%AAncia e na velhice na cena_GLS da cidade de S \%C3\%A3o Paulo - acesso em: out. 2015].

MACHADO, Frederico Viana. Muito além do arco-íris. A constituição de identidades coletivas entre a sociedade civil e o Estado. Dissertação de Mestrado em Psicologia Social. Faculdade de Filosofia e Ciências Humanas, UFMG, Belo Horizonte, 2007.

MACRAE, Edward. "Em defesa do gueto". In: GREEN, J. e TRINDADE, R. (orgs.). Homossexualismo em São Paulo e outros escritos. São Paulo, Ed. da UNESP, 2005, pp.291-308.

MEllo, Luiz. Novas famílias: conjugalidade homossexual no Brasil contemporâneo. Rio de Janeiro, Garamond, 2005. 
NEIVA, Giórgia de Aquino. Nas redes dos alternativos: mercado, sexualidade e produção de diferenças na cidade de Goiânia. Dissertação de Mestrado, Antropologia Social, UFG, Goiânia, 2014.

PERILO, Marcelo. Eles botam o bloco na rua! uma etnografia em espaços de sociabilidades juvenis. Dissertação de Mestrado em Antropologia Social, Universidade Federal de Goiás, Goiânia, 2012.

POLLAK, Michael. Memória e identidade social. Estudos Históricos vol. 5, $n^{\circ} 10$, Rio de Janeiro, 1992, pp.200-212.

RuBIN, Gayle. Thinking Sex: Notes for a Radical Theory of the Politics of Sexuality. In: VANCE, Carole. Pleasure and Danger. Exploring female sexuality. Boston: Routledge, 1984, pp.267-319.

SALLETI Filho H. et al. Vulnerabilidade e prevenção em tempos de AIDS. In: PARKER R, BARBOSA RM. (Org.). Sexualidades pelo avesso: direitos, identidades e poder. São Paulo, Ed. 34, 1999, pp.49-72.

SILVA, Tanieli de Moraes Guimarães. De bar em bar: consumo e lesbianidades em Goiânia. Relatório de Iniciação Científica. Goiânia, UFG, 2012.

SIMÕES, Júlio Assis. Homossexualidade Masculina e Curso da Vida: pensando idades e identidades sexuais. In: PISCITELLI, A.; GREGORI, M.F.; CARRARA, S. Sexualidade e Saberes: Convenções e Fronteiras. Rio de Janeiro, Garamond Universitária, 2004, pp.415-447.

SIMÕES, Júlio Assis; FACCHINI, Regina. Na trilha do arco-íris: do movimento homossexual ao LGBT. São Paulo, Ed. Fundação Perseu Abramo, 2009. 